\title{
The Aphasia Quotient: The Taxonomic Approach to Measurement of Aphasic Disability
}

\author{
ANDREW KERTESZ AND ELIZABETH POOLE
}

SUMMARY 150 aphasiacs and 59 controls were examined with a scorable, comprehensive battery, designed to be used by the clinician and the research worker. The subtests of Fluency, Information, Comprehension, Repetition and Naming were added and compared to a hypothetical normal of 100 obtaining the "aphasia Quotient." This is a measurement of the severity of language impairment. On the basis of their performance on the subtests, the patients were classified according to taxonomic principles into Global, Motor (Broca's), Isolation, Sensory (Wernicke's), Transcortical Motor, Transcortical Sensory, Conduction and Anomic groups (in order of severity). This classification is considered a clinically valid baseline for research, diagnosis and prognosis.

RÉSUMÉ 150 aphasiques et 59 contrôles furent évalués avec une batterie d'études permettant gradation, celle-ci compréhensive mais aussi pratique et préparée pour être utile autant:au clinicien qu'au chercheur. Résultats d'examens constituents individuels de Fluence, Information, Compréhension, Répétition et Identification, furent additionnés et comparés au normal cumulatif, hypothétique de 100, apportant le "Quotient d'aphasie." Ce dernier est un indice de sévérité de défaut de language. D'après leur performance à ces examens, les patients furent classifiés selon des principes taxonomiques en groupe d'aphasie Globale, Motrice (Broca), d'Isolation, Sensorielle (Wernicke) Motrice trans-corticale, Sensorielle trans-corticale, de Conduction et Anomique (en ordre de sévérité). Cette classification apporte une base valable pour recherche, diagnostic et pronostic.
Aphasia is one of the most fascinating and complex problems clinicians encounter. Some regard all aphasics alike, others make the usual distinction of expressive-receptive aphasia, popularized by Weisenburg \& McBride (1935), which is too overlapping and vague to be useful. Henry Head's (1926) classification of verbal, semantic, syntactical and nominal aphasias never gained popularity because it was difficult to apply clinically. Many psychological and linguistic studies of aphasia lack neuroanatomical correlations and are not attractive to morphologically and physiologically oriented clinicians. There is a trend recently to unify aphasic phenomena as if they were only variations of the same dysfunction. This revival of the view of Pierre Marie was contributed to by the extensive work of Schuell (1964). Our approach utilizes some of the concepts of Geschwind (1964), Goodglass (1964), Quadfasel and others, from the Boston Aphasia Unit, which have gained acceptance because of their clinical applicability.

Notwithstanding the complexity and confusion about the approaches, definitions and classifications, certain groups of patients are easily distinguished by the experienced. This study is designed to measure these clinical differences and to improve upon the arbitrary impressions of the clinician, with a comprehensive, scorable and practical test of language. Many tests to survey aphasics have been constructed and it seemed rational to choose one for the purpose of surveying aphasic pheno-

From the Department of Clinical Neurological Sciences, University of Western Ontario, St. Joseph`s Hospital, London, Ontario, Canada.

Reprint address: A. Kertesz, St. Joseph's Hospital, London, Ontario N6A 4V2. mena. After some familiarity with the Schuell (1964) and Eisenson (1954) tests, the L.M.T.A. Wepman \& Jones (1961), P.I.C.A. Porch (1971), F.C.P. Sarno, (1969) and the N.C.C.E.A. Benton (1967), we decided to modify the Boston Aphasia Examination (at that time unpublished) for our purpose Goodglass \& Kaplan (1972). It is not intended to review the merits of various tests, but the Boston Aphasia Examination appears to cover aphasic phenomena most comprehensively, while paying attention to many linguistic and behavioral aspects, consistent with clinical observation and neurological concepts. Modification of the test became necessary to suit our basically clinical and neurological approach to taxonomic grouping of aphasics.

\section{METHODS}

Our test Western Aphasia Battery (W.A.B.) is designed for research and clinical use and can be administered in an hour to most ambulant patients, although two such sessions are often required. Severely affected patients may take less time. The tests selected should present no difficulty to a patient with intact language, as attested by the scores of $59^{\circ}$ age matched controls from the same hospital population. The controls consisted of a group of "normals," that is, 21 non-brain damaged neurological patients with spinal cord disease, peripheral neuropathy, blackouts, tics, vertigo, ataxia; etc., 17 nondominant hemispheric lesions ("comparable brain damage"), and 21 patients with diffuse or dominant hemisphere or subcortical brain damage, but clinically, no aphasia. 
One hundred and fifty (150) consecutively examined aphasics from 2 General and 1 Veterans hospital were included in the study. The majority of patients (86) came from one General hospital, where all patients known to the authors to be aphasic were surveyed consecutively. This material is thought to be more comprehensive and representative of the whole scope of aphasia than previous studies on chronic patients in rehabilitation units. The great majority of the patients had cerebral infarction and were neurologically and pathologically stable. The next in frequency were tumors, followed by trauma, hemorrhage, aneurysm, and degenerative disease (Table 1). Men-

TABLE I

Distribution According To Diagnosis

\begin{tabular}{|c|c|c|}
\hline Diagnosis & Aphasics & $\begin{array}{c}\text { Controls } \\
\text { (with Brain } \\
\text { Damage) }\end{array}$ \\
\hline C.V.A. & 114 & 20 \\
\hline Tumour & 14 & 4 \\
\hline Trauma & 9 & .. \\
\hline Degenerative & 4 & 5 \\
\hline Aneurysm & 4 & . \\
\hline Hemorrhage & 2 & 1 \\
\hline A-V Malformation & 1 & 2 \\
\hline Abscess & 1 & . \\
\hline Uncertain & 1 & .. \\
\hline Parkinson's & $\cdots$ & 3 \\
\hline Korsakoff's & . & 3 \\
\hline Total & 150 & 38 \\
\hline
\end{tabular}

tally retarded and psychotic patients or those with a language barrier were not included. The controls had similar educational and language backgrounds. Intellectual levels may account for differences in some of the subtests, such as word fluency.

The sex ratio is heavily weighted - 99:51 - towards males, a difference explained mainly by the veteran population in the sample (37). Handedness was determined in all cases by a standard questionnaire: 146 were right handed and 4 were left handed.

The subtests which seemed to yield most information about the differences between aphasics were the following (See Appendix for details).

1. Fluency and prosodic value of "spontaneous" speech, elicited by answering conversational questions and describing a picture. The same questions and pictures were used for all subjects.

2. Comprehension, tested with "yes" and "no" response, pointing to ten categories of items and obeying commands of increasingly complex sentences, similar to the "token test" DeRenzi \& Vignolo (1969).

3. Repetition of words, numbers and increasingly complex sentences of high and low probability.

4. Naming of visually presented objects, word fluency, sentence completion and responsive speech. (See Discussion.)

5. Information content of spontaneous speech scored on the same material as 1 .

The scoring of the first and fifth subtests was on a 1-10 scale, according to the criteria detailed in the appendix. The other tests were more structured and the items were easily scorable for correct or partial response. By scaling the subscores to comparable levels (1-10), the percentage of normal function can be quickly calculated by adding the subscores and multiplying by 2 , when only the verbal language subtests are used, as in this study. When expressed as a percentage of a hypothetical normal score of 100 , we call it Aphasia Quotient (A.Q.). It indicates the functional severity of speech disturbance and serves as a numerical measure of improvement or effect of therapy.
We grouped patients according to test scores, following the principles of numerical taxonomy, used in the biological classification of species. According to this principle, numerical criteria are established which allow a meaningful separation of subgroups with the greatest similarities on the basis of differential criteria. In our instance, the major criteria were chosen - fluency, comprehension, repetition and naming. According to the scores obtained, all patients were unequivocally classified. Table II contains the summary of these criteria. This table reflects the range of scores as well. They have been determined to include all test scores, after the basic criteria for the separation of subgroups were established. Fluency below 5 separated the aphasias with significant motor involvement: Global, Motor, Isolation and Transcortical Motor aphasia. Those with comprehension better than 4 on our battery separated Broca's or Cortical Motor aphasia from Global aphasia, and Transcortical Motor from Isolation aphasia. The latter two are distinguished from the former two by better than 5 repetition. Among the fluent aphasias, the Anomic and Conduction aphasics have better than 7 comprehension, in contrast to cortical (Wernicke) and Transcortical Sensory aphasics, with poor comprehension. Repetition below 7 clearly separates Conduction aphasics from Anomics. Interestingly enough, some of the Conduction aphasics

\begin{tabular}{|lcccc|}
\hline \multicolumn{5}{c|}{ TABLE II } \\
& Criteria for Classification & & \\
& & & \\
Global & Fluency & Comprehension & Repetition & Naming \\
Broca's & $0-4^{*}$ & $0-3.9$ & $0-4.9$ & $0-6$ \\
Isolation & $0-4$ & $4-10$ & $0-7.9$ & $0-8$ \\
Transcortical Motor & $0-5$ & $0-4$ & $5-10$ & $0-6$ \\
Wernicke's & $0-5$ & $5-10$ & $8-10$ & $0-8$ \\
Transcortical Sensory & $5-10$ & $0-6.9$ & $0-7.9$ & $0-7$ \\
Conduction & $5-10$ & $0-6.9$ & $8-10$ & $0-9$ \\
Anomic & $5-10$ & $7-10$ & $0-6.9$ & $0-9$ \\
*The numbers are raw scores. & $5-10$ & $7-10$ & $7-10$ & $0-9$ \\
& & & & \\
\hline
\end{tabular}


appear to have excellent naming. Naming score below 9.0 was arbitrarily chosen as a cut-off point, to separate Anomic aphasics from nonbrain damaged controls; otherwise, the naming scores did not distinguish between subgroups.

Standard (Z) scores were obtained to compare the subtests in each aphasic group. However, the scoring of subtests was designed to relate to difficulty levels and the subtests were chosen to represent equally important language functions, in order to arrive at a numerical value (A.Q.) which does not require statistical transformation by the clinician. (See Results and Fig. 2.)

\section{RESULTS}

Table III summarizes the number of patients in each subgroup, their mean age, scores by subtests and by aphasia quotient (A.Q.). The various entities are ranked in the order of severity, as determined by their A.Q.

1. Global aphasia is the most severe form. It is commonly seen (26) - Mean A.Q. = 10.5. These patients are severely affected in all language functions. They are non-informative, non-fluent, have poor comprehension, repetition and naming. They may produce variable amounts of stereotypic utterances, and at times, well pronounced and even long (2-3 words) lexical items of emotional charge, often swear words.

2. Cortical motor aphasia or Broca's aphasia is characterized by impaired speech output with relatively well preserved comprehension. They speak little, with great effort, often showing frustration but convey some information. Phonemic paraphasias and aggrammatisms are common. Repetition and naming are impaired but at times, better than spontaneous speech output. 24 cases were seen, with a Mean A.Q. of 31.7.

3 . Isolation aphasia or speech isolation syndrome is a recently described entity, with little or no spontaneous speech, comprehension or naming, but excellent repetition. Only 5 partial or incomplete examples were encountered - Mean A.Q. $=34.3$.

4. Cortical sensory aphasia or Wernicke's aphasia is characterized by fluent, paraphasic speech with impaired comprehension, repetition and naming. Some of these patients have a great amount of neologistic paraphasias, under pressure at times and often, without too much awareness of disability. (These patients are often misdiagnosed as psychiatric disturbances.) These we prefer to separate as jargon aphasics but for the purpose of this study, they are combined with this group because their performance on the verbal subtests is similar. "Pure", word deafness, meaning impaired comprehension but otherwise intact speech, repetition and naming, was seen in 2 patients, but only transiently, 28 cases belong to this group, with a mean A.Q. of 39.1.

5. Transcortical motor aphasia is an interesting entity characterized by good comprehension and excellent repetition, but the patient speaks very little on his own. This is more often seen transiently and by the time the patients are tested, there is often only slight anomia left or even that has recovered. 4 cases were considered to represent this group with a Mean A.Q. of 54.4.

6. Transcortical sensory aphasia is fluent with good repetition but poor comprehension and naming. This can also be regarded as the sensory component of the speech "isolation syndrome." 8 cases were seen Mean A.Q. $=59.5$.

7. Conduction aphasia, also called "central aphasia"' is distinguished by very poor repetition with a relatively fluent but paraphasic speech and good comprehension. This group of aphasics is most interesting and has been paid little attention in the literature until recently. One reason is that they are infrequent and the other is that repetition has to be tested speci-

\section{TABLE III}

The Number, Mean Ages, Mean Scores of Subtests and A.Q.'s and their Standard Deviations of the Subgroups and the Total of 150 Aphasics and 59 Controls

\begin{tabular}{|c|c|c|c|c|c|c|c|c|c|c|c|c|c|c|}
\hline \multirow[b]{2}{*}{ No. } & \multirow[b]{2}{*}{ Type of Aphasia } & \multirow{2}{*}{$\underset{X}{\text { Age }}$} & \multicolumn{2}{|c|}{ Fluency } & \multicolumn{2}{|c|}{ Comprehension } & \multicolumn{2}{|c|}{ Repetition } & \multicolumn{2}{|c|}{ Naming } & \multicolumn{2}{|c|}{ Information } & \multicolumn{2}{|c|}{ A.Q. } \\
\hline & & & $\mathrm{x}$ & S.D. & $x$ & S.D. & $\mathrm{x}$ & S.D. & $\mathrm{x}$ & S.D. & $\mathrm{x}$ & & & \\
\hline 26 & Global & 65.0 & 1.0 & 1.2 & 2.2 & 1.7 & 0.9 & 1.5 & 0.5 & 1.3 & 0.6 & 0.9 & 10.5 & 9.2 \\
\hline 24 & Motor (Broca's) & 57.3 & 2.5 & 1.7 & 5.9 & 1.5 & 3.3 & 3.1 & 2.4 & 2.4 & 1.8 & 1.8 & 31.7 & 16.6 \\
\hline 5 & Isolation & 65.6 & 3.0 & 1.7 & 2.5 & 1.0 & 7.8 & 1.7 & 2.1 & 1.7 & 1.8 & 1.1 & 34.3 & 11.9 \\
\hline 28 & Sensory (Wernicke's) & 60.3 & 6.9 & 1.1 & 3.5 & 1.9 & 3.7 & 3.0 & 2.1 & 1.8 & 3.3 & 2.3 & 39.0 & 12.8 \\
\hline 4 & Transcortical Motor & 67.0 & 3.5 & 1.0 & 6.2 & 1.3 & 9.2 & 0.9 & 4.3 & 2.4 & 3.5 & 1.0 & 54.4 & 8.4 \\
\hline 8 & Transcortical Sensory & 51.3 & 6.9 & 1.4 & 4.9 & 1.3 & 9.3 & 0.5 & 4.0 & 2.5 & 4.6 & 1.3 & 59.6 & 5.5 \\
\hline 15 & Condition & 62.2 & 6.1 & 1.2 & 8.3 & 0.9 & 5.0 & 1.9 & 5.2 & 2.6 & 5.7 & 2.2 & 60.5 & 12.7 \\
\hline 40 & Anomic & 60.3 & 8.0 & 0.9 & 9.0 & 0.8 & 9.1 & 0.9 & 7.8 & 1.2 & 7.7 & 1.7 & 83.3 & 7.8 \\
\hline 150 & Total X & 61.1 & 5.2 & 3.0 & 5.7 & 2.9 & 5.3 & 3.8 & 3.9 & 3.3 & 4.0 & 3.2 & 48.2 & 28.2 \\
\hline & Controls & & & & & & & & & & & & & \\
\hline 21 & I Non-Brain Damaged & 59.2 & 10.0 & 0.0 & 9.9 & 0.2 & 9.8 & 0.3 & 9.5 & 0.3 & 10.0 & 0.0 & 98.4 & 1.0 \\
\hline 17 & II Non-Dominant & & & & & & & & & & & & & \\
\hline & $\begin{array}{l}\text { Hemisphere } \\
\text { Mixed Groun }\end{array}$ & 59.4 & 10.0 & 0.0 & 9.7 & 0.4 & 9.8 & 0.2 & $\begin{array}{l}9.1 \\
80\end{array}-10$ & $\begin{array}{l}0.4 \\
0.5\end{array}$ & 9.9 & 0.3 & $\begin{array}{l}97.1 \\
03.8\end{array}-120$ & 1.9 \\
\hline & & 38.6 & 9.7 & 0.7 & 9.5 & 0.6 & 9.6 & 0.3 & 8.9 & & & & 93.8 & 4.7 \\
\hline
\end{tabular}




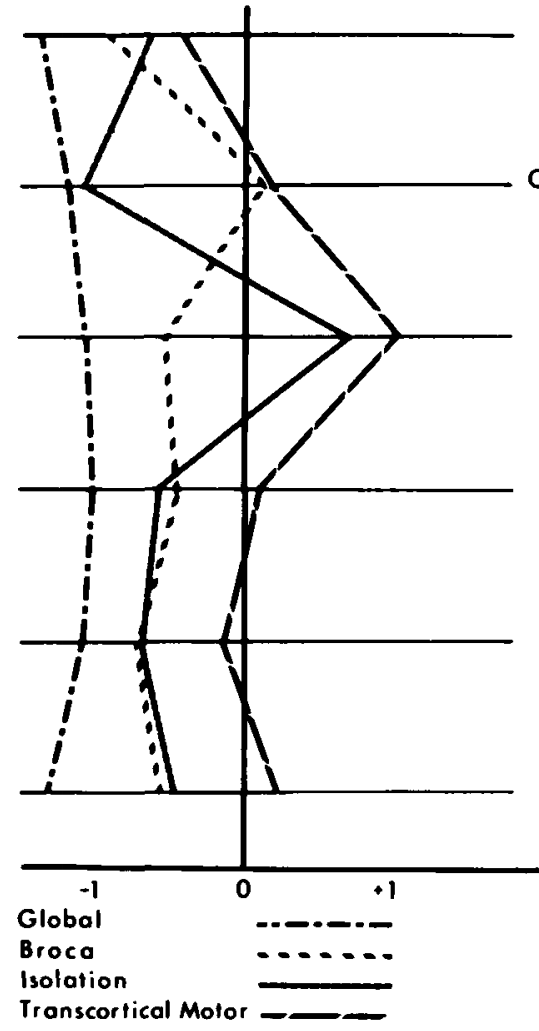

Figure I-The profile of performances using standard $(\mathrm{Z})$ scores (abscissa):

fically to identify them. There were 15 patients with a Mean A.Q. of 60.6.

8. Anomic or amnestic aphasia was common. These patients have fluent, often circumlocutory speech, associated with good comprehension and repetition but impaired naming. Some patients included in this study performed near normal on naming tasks, in spite of word finding difficulty. There are also a few patients whose spontaneous speech was very near normal but who had significant impairment of naming on visual stimuli. These may represent a pure stimulus-response defect. They were rechecked on a control subtest involving naming by palpation, to see if there was significant difference between the two input modalities for naming, such as may occur in visual agnosia. 40 cases were seen, with a Mean A.Q. of 83.3.

A profile of performance for each aphasic subgroup was drawn using standard (Z) scores (Fig. 1). This illustrates the outstanding features of each aphasic group which is the basis of the presented classification.

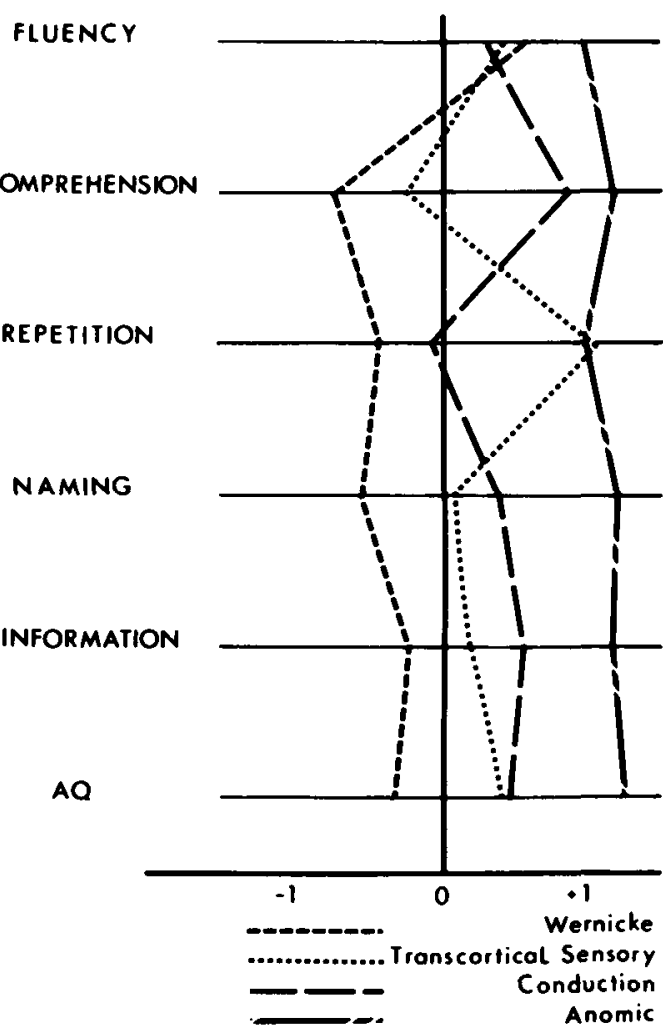

Non-fluent aphasics on the left, fluent ones on the right.

The difficulty levels of each subtest were quite comparable, as attested by the similarity of means and standard deviations attained by 150 aphasics (Fig. 2).

\section{FLUENCY}

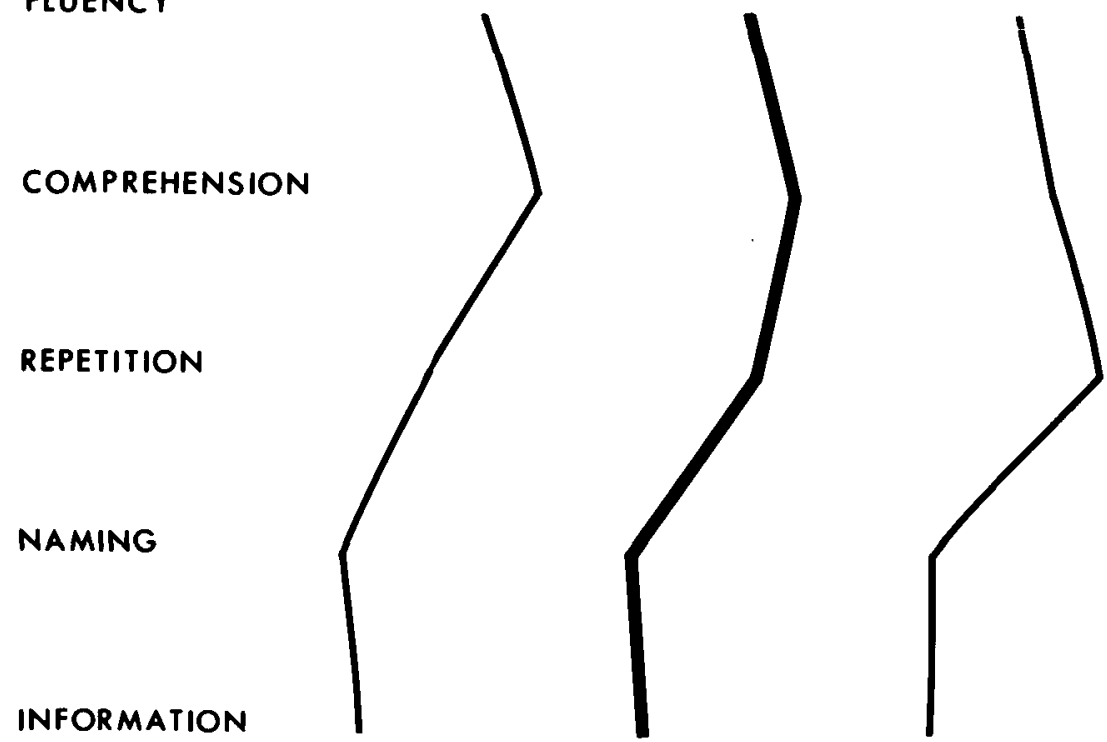

The ages of various aphasic and control groups were subjected to one-way analysis of variance and were found to be not significantly different from each other. ( $F=1.35$ at 10 and $198 \mathrm{df}$.)

\section{DISCUSSION}

These results indicate the proportion of aphasics belonging to each subgroup and the severity of their communication deficit, as determined by the A.Q. The subtest which correlated best with A.Q. was information, although it did not contribute significantly to classification into various types. Reading and writing, although tested whenever possible, were not used for the purpose of this study, because they tended to parallel the oral language disturbance, e.g. a cortical motor aphasic had just as much trouble writing as speaking and cortical sensory aphasics produced as much jargon in reading aloud as in their speech and seemed to have as much trouble understanding print as verbal stimuli. The occasional jargon patient showed an interesting phenomenon; graphorrhea or writing of copious, unintelligible jargon, an example of which has been published. (Kertesz \& Benson, 1967). Exceptions to this occur, however, such as cases of "pure word

INFORMATION

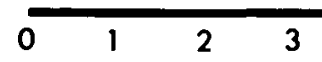

Figure 2-The means and standard deviations for each subtest, using raw 
deafness," who understand written material better.

The basis of our classification was to choose outstanding clinical characteristics which would be found in each member of the group. Such characteristic constants are well known in biology as "natural taxons" and form the basis of classification of species of animals and plants. The principles of numerical taxonomy establish the existence of constant characteristics, while varying in an uncorrelated manner in other subgroups Sokal \& Sneath (1963). Some of these characteristics are agreed upon by almost everyone dealing with aphasia.

Fluency appears to be one of the most important factors differentiating various aphasics Benson (1966), Kerschensteiner, Poeck, Bruner (1972), Howes \& Geschwind (1964). We rated fluency according to set criteria (See Appendix b) applied to the "spontaneous speech," elicited by recording the responses to standardized questions and by asking the patient to describe a picture (a simple drawing of a house, a pond, people and animals, used by Schuell).

Comprehension of language is not a simple, unitary function and there are many ways to test it. The most traditional is to ask the subject to point to items. We used objects, pictures of objects, body parts, letters, numbers and colors. The instructions were standardized. Multiple choice of 6 was usually offered, although in a few items, such as pointing to furniture and body parts, the patient had greater choice. The auditory stimulus was only one word (auditory recognition).

It has become evident that although some aphasics (motor or Broca's) do very well, on the auditory recognition tasks, almost all aphasics except some Anomic, Transcortical Motor and Conduction aphasics will have difficulty with sequentially presented items. This task is variously called auditory retention span or auditory sequencing and its significance has been recognized by Pierre Marie, who measured comprehension with the "three paper test," essentially an auditory sequencing test, similar to our "commands with auditory sequencing." The recently popular token test is a long, complicated version of the same task, and even some normal controls find it difficult to do. Our test also utilizes the important observations of Goodglass et al (1970) on the importance of relational words.

The use of "yes" and "no" responses avoids the pointing difficulty or apraxia the patient may have in carrying out the auditory sequencing task. Unfortunately, for some aphasics a considerable amount of "yes" and "no" confusion may exist. That this may be a phenomenon beyond and separate from comprehension difficulty, more aligned with apraxia, is evidenced by the frustrated, corrective behaviour of many global aphasics, most often exhibiting "yes" and "no" confusion. They often indicate by gestures that they meant "yes" when they said "no." This response is often spontaneous and not in response to the examiner's inadvertent disapproval. It is also frequently wrong, that is, the patient may be frustrated with the correct answer!

Repetition is essential to distinguish conduction and transcortical aphasics clinically from other sensory and motor aphasics. The repetition task utilized single words, sentences, numbers, and number-word combinations. The words and sentences were chosen to represent a difficulty gradient for length, probability and articulatory facility. Scoring considers errors in order, as well as phonemic substitutions. Most clinicians will concur that there are patients who have great difficulty comprehending or producing spontaneous speech but nevertheless, repeat exceedingly well. To separate these cases from the larger group of sensory and motor aphasics has a valid foundation in clinical experience, as attested by our data, regardless of the theoretical implication of disconnection of speech region from other association areas. Repetition is regarded as a function of the intact speech area alone Geschwind, Quadfasel \& Segarra (1968). These aphasics were relatively se- verely affected, especially those in the isolation group (A.Q. of 34.3) but their repetition was disproportionately better over other features. The mean repetition scores of isolation aphasics were 7.8 , compared with their fluency 3.0, comprehension 2.5 and naming 2.1. Transcortical motor aphasics had mean repetition of 9.2 and low fluency -4.00 but better comprehension- 6.2 and transcortical sensory aphasics had mean repetition scores of 9.3 with fluent, spontaneous speech scores of 6.9 , compared with relatively poor comprehension scores of 4.9. One does not have to see too many transcortical motor aphasics, who are practically mute, except when it comes to repetition, or transcortical sensory aphasics, who do not understand anything but repeat well, to believe in the existence of a substantial difference between these and the more common varieties of aphasia. The terms "cortical" and "transcortical" are used here for the sake of tradition rather than to denote established anatomical differences.

The naming tasks, used for all subjects, included confrontation with visual stimulus $-60 \%$ of the naming score; word fluency-20\% sentence completion-10\% and responsive speech-10\%. These correspond to various items at N.C.C.E.A. Benton (1967). The last 2 items, comprising $20 \%$ of the naming score, probably require auditory sequencing as well as word finding. The first item consists of naming objects, pictures of objects, geometric figures, letters, numbers, body parts, colors, national symbols, punctuation marks, etc. This requires relatively little comprehension, provided the patient understands the initial instruction and stays with the "set." Many of these items were the same as used on the pointing task for comprehension. The large number of items were designed to detect cases of specific naming problems for colors, numbers, body parts, etc. or cases of " asymbolia." Such specific naming defects are the subject of another study. For the purposes of this study and clinical use, we decided to use the shortened version only; that is, the naming of $20 \mathrm{com}$ - 
mon objects. These were selected for their availability and handy size but variations of the shape and the category of the objects and difficulty level ("expectation or frequency or occurrence"') were introduced deliberately. (See Appendix g). The word fluency item was very sensitive to aphasic disturbances of word finding but also seemed to depend on intelligence, degree of relaxation and concentration and probably, on educational levels as well. Many "controls" with otherwise normal language did poorly on this task, indicating the role of non-language factors.

The rating of paraphasias proved to be extremely difficult. Linguistic studies of phonemic and verbal substitutions are rarely quantitative Lecours \& Lhermitte (1969). However, the amount of neologistic output clearly separates jargon aphasics from the rest of cortical sensory aphasics Kertesz \& Benson (1970), although for the purpose of this study, they are kept together. Conduction aphasia will have a higher rate of phonemic paraphasias than sensory aphasia (with the exception of jargon aphasics), transcortical sensory, and anomic aphasias and this deserves further quantitative study. Another area where rating of paraphasias may be useful is to distinguish mild or recovered cases of sensory aphasias from normals because their scores on the battery would be within normal range.

There is a group of recovered or mild aphasics, whose word finding difficulty or the occasionally uttered paraphasias would justify regarding them with the aphasic group clinically but their performance on the battery is in the normal range. For the purpose of this study, we did not include them in the aphasic group, although for some individuals, this so called "normal" performance was probably below their usual language ability. Since they were referred to us as either questionable aphasics or known but recovered aphasics, we could not include them in the normal group either.

All our aphasics differed from the "non-brain damaged controls" in that either their fluency score was below 10 or their naming fell below 9.0. (There was one mildly anomic patient whose fluency was scored as 10 but his naming on confrontation was only 7.9.) The lowest naming score for the non-brain damaged controls was 9.1. The controls were comparable in age and since they were taken consecutively from the same hospital population, probably for other socio-economic factors as well. The control of educational levels would be more important in the reading and writing tasks, which were not surveyed here. The majority of patients was tested on Raven's Colored Progressive Matrices, also a non-verbal test of intelligence. The performance of aphasics was comparable to the controls, suggesting that the population was matched for intelligence as well Kertesz (1973).

Overlapping scores were observed with the third group of controls examined on the battery. The border appeared indistinct between this group and recovering mild anomic aphasics. A comparison with aphasics seemed to be worthwhile, because of the problem of drawing the line between diffuse brain damage affecting language and aphasia. The group consisted of 3 cases of Parkinsons's Disease with dementia, 3 cases of Korsakoff's Psychosis, 5 cases of Subcortical or Brainstem Infarcts, 3 cases of Presenile Dementia-2 presumed to be Alzheimer's clinically-1 proven Jakob-Creutzfeldt on autopsy, 2 Left Hemisphere Tumours - 1 Parietal Glioma (Gerstmann Syndrome without aphasia)-1 Parasagittal Meningioma, 1 Postconcussion Syndrome, 1 Postencecephalitic and 3 patients with the diagnosis of "organic dementia." Common to them was diffuse, dominant hemisphere or subcortical brain damage and no obvious difficulty with language. Some of the presenile dementias, of course, involve the speech areas sooner or later in the course of the disease, although they are not as likely to present with aphasia. The implication of verbal memory loss in Korsakoff's Disease as a factor in the mild anomia seen is of theoretical interest to the mechanism of anomia. The whole group had a higher Mean A.Q. (93.8-S.D.= 7.8) than anomic aphasia (83.3 - S.D. $=4.3$ ), the least severe of aphasic groups. The difference is very significant at $P<0,0005$ level, using Student's " $t$ " " test ( $t=5.7$ at $59 \mathrm{df})$. Since the control group has a smaller sample size but also smaller variance, the calculated $t$ ratio is likely to be smaller than the tabled probability levels.

Determination of A.Q. seems useful to distinguish between aphasic and non-aphasic, brain damaged patients. An operational definition of aphasic score may be provided by the above control scores. The patient may be considered normal if the A.Q. is 95 or above. The most useful, single subtest seems to be the fluency rating, where all the controls achieved 10 .

This study did not account for the change in aphasic performance with time. It has been recognized that the rate of recovery among various subgroups is different; for example, global aphasics usually remain severely disabled while transcortical motor aphasics, although often mute on admission, recover within weeks. Sensory aphasics often go through a predictable course of evolution. This is a subject for further quantitative study using the above method.

Recently, evidence for distinct localization of the lesions in each of the sub-groups has been accumulated, suggesting that the classification presented above, although far from final, could be a diagnostic tool for the neurologist.

\section{ACKNOWLEDGMENTS}

The authors would like to thank the physicians who referred the cases for study, J. McGlone for some of the testing and computations and P. McCabe and C. Spencer for their assistance.

Lea and Febiger gave permission to reproduce parts of the Boston Aphasia Examination - Appendix a, parts of Appendix d, e, f, i, j, k.

\section{REFERENCES}

BENSON, D. F. (1967) Fluency in aphasia: correlation with radioactive scan localization. Cortex, 3, 373-394. 
BENTON, A. L. (1967) Problems of test construction in the field of aphasia. Cortex, 3, 32-58.

DeRENZI,E.andVIGNOLO,L.A.(1962) The token test: a sensitive test to detect receptive disturbances in aphasics. Brain, 85, 665-678.

EISENSON, J. (1954) Examining for Aphasia. New York: The Psychological Corporation.

GẺSCHWIND, N. (1965) Disconnexion syndromes in animals and man. Brain, 88, 237-294 and 585-644.

GESCHWIND,N.,QUADFASEL,F.and SEGARRA, J. (1968) Isolation of the speech area. Neuropsychologia, 6, 327-340.

GOODGLASS, H., QUADFASEL, F. and TIMBERLAKE, W. (1964) Phrase length and the type and severity of aphasia. Cortex 1, 131-153.

GOODGLASS, H., GLEASON, J. and Hyde, M. (1970) Some dimensions of auditory language comprehension in aphasia. J. Speech and Hearing Res., 13, 595-606.

GOODGLASS, H., KAPLAN, E. (1972) The assessment of aphasia and related disorders. Philadelphia: Lea and Febiger.

HEAD, H. (1926) Aphasia and kindred disorders of speech. New York: MacMillan.

HOWES, D. and GESCHWIND, N. (1964) Quantitative studies of aphasic language. Ass. Res. Nerv. Ment. Dis., 42, 229-244.

KERSCHENSTEINER, M., POECK, K. and BRUNNER, E. (1972) The fluency-nonfluency dimension in the classification of aphasic speech. Cortex 8, 233-247.

KERTESZ, A. and BENSON, D. F. (1970) Neologistic jargon: a clinicopathological study. Cortex 6, 362-387.

KERTESZ, A. (1973) Intelligence and aphasia. Trans. Am. Neurol. Ass. In press.

LECOUR, A. R. and HERMITTE, F. (1969) Phonemic paraphasias: linguistic structures and tentative hypothesis. Cortex, 5, 193-229.

PORCH, B. (1971) Porch Index of Communicative Ability. Palo Alto: Consulting Psychologists Press.

SARNO, M. T. (1969) The functional communication profile. Manual of directions. Rehabilitation Monograph 42. New York: Institute of Rehabilitation Medicine.

SHUELL, H., JENKINS, J. J. and JIMENEZ-PABON, E. (1964) Aphasia in Adults. New York: Harper and Row.

SOKAL, R. R. and SNEATH, P. H. A. (1963) Principles of Numerical Taxonomy. San Francisco: W. H. Freeman \& Son.

WEISENBURG, T. and McBRIDE, K. E. (1935) Aphasia. New York: The Commonwealth Fund.

WEPMAN, J. M. and JONES, L. V. (1961) The language modalities test for aphasia. Chicago: EducationIndustry Service.

\section{APPENDIX a}

\section{I-Spontaneous Speech:}

Record patient's speech verbatim, on paper, preferably, on tape. Substitute similar questions if necessary.

1. How are you today?

2. Have you been here before? or Have I tested you before?

3. What is your full name?

4. What is your full address? (Accept any response which includes correct street and number or street and city.)

5. What kind of work did you do before you became ill?

6. Tell me a little about why you are here? or What seems to be the trouble?

7. Presentation of picture. Show the test picture and tell patient to "Tell everything you see going on in this picture." Point to neglected features of the picture and ask for elaboration if patient's response is skimpier than his apparent potential. A minute should be allowed.

(The simple drawing from Schuell's test - a house, a pond with people and animals - is shown.)

\section{APPENDIX $b$}

\section{Scoring of Spontaneous Speech}

\section{A. Rating of Information}

(10) Correct responses to all 6 items on page 2 , on number 7 , sentences of normal length and complexity, integrating people and action in the picture, and referring to at least 3 of the principle activities. No perceptible circumlocution or word finding difficulty.

(9) Correct responses to all 6 items on page 2. Some sentences or longer phrases used in integrating people and actions of the picture (No. 7), at least 10 important people, objects or actions should be named.
(8) Same as above with much circumlocution and word finding difficulty.

(7) Correct response to 5 of the first 6 items, incomplete description of the picture.

(6) Correct response to 4 of the first 6 items on page 2 , and mention at least 6 of the key nouns or verbs in the picture (No. 7) with some meaningful grouping of words into phrases.

(5) Any 4 of all items.

(4) Any 2 of the first 6 items plus some response to 7 .

(3) Response to 3 items.

(2) Only response to any 2 items.

(1) Only response to any one question.

(0) No information.

\section{B. Rating of Fluency}

(10) Sentences of normal length and complexity, without perceptible deliberation about grammatical usage. No perceptible halting or distortion of rhythm in phrasing.

(9) Tendency to simplify sentences, or leave longer sentences incomplete; hesitation over particles of speech, auxiliary verbs or word-endings. Some paraphasias. Some word finding difficulty.

(8) Circumlocutory, fluent speech. Obvious word finding difficulty. Semantic jargon.

(7) Phonemic jargon with semblance to English syntax and rhythm with varied phonemes and neologisms.

(6) Predominantly telegraphic speech, but some grammatical organization. Normal rhythmic patterning may be present within phrases, but does not connect phrase to phrase.

(5) Many paraphasias and halting speech but some sentences well constructed and pronounced. (Similar but worse than 6.)

(4) Predominantly single words, but with occasional verbs or prepositional phrases.

(3) Fluent recurrent utterances or mumbling, very low volume jargon.

(2) Single words, often inappropriately used or recurrent utterances used in a meaningful way.

(1) Recurrent utterances with meaning.

(0) No words or short, meaningless utterances. 


\section{APPENDIX c}

\section{Auditory Verbal Comprehension}

a. Yes and No Task - ask patient to answer these questions with yes or no only. Make certain he understands the task and if he does not comply, remind him. Note if patient seems to understand but appears to have "Yes and No Confusion." In this case, eye closure for "yes" may be substituted with improvement of the score. If the patient corrects himself, accept it, but if both responses are given, score 0 . Score $1 \frac{1 / 2}{2}$ for each correct answer.

1. Is your name Smith?

\begin{tabular}{crr} 
& Answer & Correctness \\
\hline Verbal & Gestural & Eye Blink \\
\hline
\end{tabular}

2. Is your name Brown?

3. Is your name (real name) ?

4. Do you live in Toronto?

5. Do you live in (real residence) ?

6. Do you live in Windsor?

7. Are you married?

8. Do you have children?

9. Are the lights on in this room?

10. Is the window closed?

11. Is this a hotel?

12. Is this St. Joseph's Hospital?

13. Are you wearing red pyjamas?

14. Will a stone sink in water?

15. Do you eat lunch before supper?

16. Do you eat a banana before you peel it?

17. Does it snow in July?

18. Is a lion larger than a dog?

19. Is a hammer good for cutting wood?

20. Are you a doctor?

Maximum Score - 30

Patient's Score

\section{APPENDIX d}

\section{b. Word Discrimination Task}

Present real objects, color cards. Ask patient to point to each object or his own body part by saying, "Show me the . . . or Point to the ..." Only one repetition of the command is permitted, if no response or patient asks. If the patient points to more than one item, score 0 , unless it is clear that the patient recognizes his mistake and firmly chooses one after correcting himself. Score $1 / 2$ for each correct.

\begin{tabular}{|l|l|l|l|l|l|l|l|l|l|}
\hline \multicolumn{2}{|c|}{ Real Objects } & \multicolumn{2}{c|}{ Pictured Objects } & \multicolumn{2}{c|}{ Forms } & \multicolumn{2}{c|}{ Letters } & \multicolumn{2}{c|}{ Numbers } \\
\hline Key & & Helicopter & & Circle & & L & & 7 & \\
\hline Feather & & Key & & Spiral & & H & & $42 \cdot$ & \\
\hline Pencil & & Comb & & Square & & R & & 700 & \\
\hline Cactus & & Feather & & Triangle & & T & & 1936 & \\
\hline Comb & & Pencil & & Cone & & S & & 15 & \\
\hline Helicopter & & Cactus & & Star & & G & & 7000 & \\
\hline
\end{tabular}

\begin{tabular}{|l|l|l|l|l|l|}
\hline \multicolumn{2}{|c|}{ Colors } & \multicolumn{2}{|c|}{ Body Parts } & & \\
\hline Blue & & Ear & & Window & \\
\hline Brown & & Nose & & Chair & \\
\hline Red & & Eye & & Desk (Table) & \\
\hline Green & & Chest & & Light & \\
\hline Yellow & & Neck & & Door & \\
\hline Black & & Chin & & Ceiling & \\
\hline
\end{tabular}


c. Fingers and Right and Left Discrimination

(May present your own fingers if necessary)

\begin{tabular}{|l|l|l|l|}
\hline Thumb & & Left Shoulder & \\
\hline Ring Finger & & Left Knee & \\
\hline Index Finger & & Right Ankle & \\
\hline Little Finger & & Right Wrist & \\
\hline Middle Finger & & Left Elbow & \\
\hline Right Ear & & Right Cheek & \\
\hline
\end{tabular}

Maximum Score - 30

Patient's Score

\section{APPENDIX e}

Commands with Auditory Sequencing

Have the patient carry out the following commands, giving credit for each underlined element which he carries out. One repetition is permitted on request, but command must always be repeated as a whole - not broken up.

Make a fist.

Shut your eyes.

Point to the chair.

Point to the ceiling, then to the floor.

1

(After lining up a pencil, watch and card, in that order, on the table before the patient.)

Point to the pencil and the card.

Point with the pencil to the 2 ard.

Point to the pencil with the card.

Point to the watch with the pencil.

With the card point to the watch.

$$
2 \text {. } 2
$$

Put the pencil on top of the card, then put it back.

$$
244
$$

Put the watch on the other side of the pencil and turn over the card.

Maximum Score

Patient's Score

\section{APPENDIX $\mathbf{f}$}

\section{Repetition}

Ask patient to repeat: record answer verbatim. May repeat items once, if patient asks for it or does not seem to hear. If incompletely repeated, score 2 for each recognizable word. Take 1 off for errors in order or literal paraphasia.

$\begin{array}{lc} & \begin{array}{c}\text { Maximum } \\ \text { Score }\end{array} \\ \text { 1. Chair } & 2 \\ \text { 2. Nose } & 2 \\ \text { 3. Pipe } & 2 \\ \text { 4. Window } & 2 \\ \text { 5. Banana } & 2 \\ \text { 6. Snowball } & 4 \\ \text { 7. Two } & 2 \\ \text { 8. Forty-five } & 4 \\ \text { 9. Ninety-five percent } & 6\end{array}$

10. Sixty-two and a half

11. The telephone is ringing

12. He is not coming back

13. The spy fled to Greece

14. First British Field Artillery

15. No ifs ands or buts

16. The quick brown fox jumps over the lazy dog

Maximum Score 100 Patient's Score

\section{APPENDIX $g$}

V. Naming

Score 3 if correctly named, $1 / 2$ if required a cue or named the object on a second attempt. Give credit for recognizable paraphasias. May try tactile naming for the objects missed.

\begin{tabular}{|l|l|l|l|}
\hline \multicolumn{1}{|c|}{ Objects } & Score & $\begin{array}{c}\text { Ist } \\
\text { Attemp }\end{array}$ & $\begin{array}{c}\text { 2nd } \\
\text { Attempt }\end{array}$ \\
\hline 1. Gun & & & \\
2. Ball & & & \\
3. Knife & & & \\
4. Cup & & & \\
5. Pin & & & \\
6. Hammer & & & \\
7. Toothbrush & & \\
8. Eraser & & \\
9. Padlock & & \\
10. Pencil & & \\
11. Screwdriver & & \\
12. Key & & \\
13. Paper Clip & & \\
14. Pipe & & \\
15. Comb & & \\
16. Elastic & & \\
17. Spoon & & \\
18. Tape & & \\
19. Fork & & \\
20. Matches & & \\
\hline Maximum Score: 60 & \\
Patient's Score: ...... & \\
\hline
\end{tabular}

\section{APPENDIX $h$}

\section{i. WORD FLUENCY}

Ask patient to name as many animals as he can in 1 minute. (Normals may score 18 or more.) He may be helped if hesitant: "Think of domestic animals, like the dog or animals in the jungle, like a tiger." At this point, he should be timed.

Maximum Score - 20

Patient's Score ......

\section{j. SENTENCE COMPLETION}

1. The grass is (green).

2. Sugar is ..(sweet).

3. Roses are red, violets are (blue).

4. They fought like cats and (dogs).

5. Christmas is in the month of...... (December).

Maximum Score - 10 Patient's Score 


\section{k. RESPONSIVE SPEECH}

1. What do you tell time with? (Watch, 4. What do you do with soap? (Wash) Clock)

2. What color is coal? (Black)

3. How many things in a dozen? (Twelve)

5. Where do you go to buy medicine? (Drug Store, Pharmacy)

Maximum Score - 10

Patient's Score ......
APPENDIX i

Score Sheet

$\begin{array}{ccc} & \text { Patient's } & \\ \text { Maximum } & \text { Subscores } & \text { Total }\end{array}$

Spontaneous Speech:

Information

Fluency

$\begin{array}{ll}10 & \ldots \\ 10 & \ldots\end{array}$

Total $\overline{20}$

Comprehension:

Yes - No

Word Discrimination

Commands (Objects)

(Divide by 10)

30

$30 \quad \ldots$

$\begin{array}{ll}30 & \cdots \\ 40 & \cdots\end{array}$

Repetition:

(Divide by 10)

Total $\overline{10}$

Naming:

Object Naming

Word Fluency

Sentence Completing

Responsive Speech

Total 10

(Divide by 10)

60

60
20

10

10

....

....

Total $\overline{10}$

Add and Multiply by 2 A.Q.

A.Q. 